\title{
Effect of Phosphoric Acid on the Polycondensation of Bis(2-hydroxyethyl) Terephthalate Catalyzed by Sb(III) Compounds
}

\author{
Hiroyoshi Kamatani, ${ }^{*}$ Shigeji Konagaya, ${ }^{*}$ and Yoshiyuki NAKAmURA** \\ *Katata Research Center, Toyobo Co., Ltd., \\ 1300-1 Honkatata, Otsu 520-02, Japan. \\ ** Research Laboratory of Resources Utilization, Tokyo Institute of Technology, \\ Nagatsuta-cho, Midori-ku, Yokohama 227, Japan.
}

(Received September 14, 1979)

\begin{abstract}
The influence of phosphoric acid on the activity of $\mathrm{Sb}$ (III) catalyst was studied in the catalytic polycondensation of bis(2-hydroxyethyl) terephthalate (BHET). Although the rate of polycondensation in the initial stage was depressed by the addition of phosphoric acid to the Sb(III) catalyst, subsequent polycondensation was accelerated to give a higher-molecular-weight poly(ethylene terephthalate) as compared with that obtained in the absence of phosphoric acid. The yield of by-products in the polycondensation was also affected by the addition of phosphoric acid; the formation of acetaldehyde decreased, and that of the diethylene glycol unit increased. It was made clear from studies of ${ }^{31} \mathrm{P}$ NMR that the phosphoric acid was converted into phosphate $\left(\mathrm{O}=\mathrm{P}\left(\mathrm{OC}_{2} \mathrm{H}_{4} \mathrm{OR}\right)_{3}\right)$ in the early stage of the polycondensation by reaction with BHET or ethylene glycol which was generated in the polycondensation of BHET. It is assumed that the modification of the polycondensation reaction caused by the addition of phosphoric acid is due to the complexation of $\mathrm{Sb}$ (III) catalyst with the phosphate. The mechanism for the polycondensation of BHET catalyzed by $\mathrm{Sb}(\mathrm{III})$ compounds in the presence of phosphoric acid was proposed on the basis of these findings.

KEY WORDS Bis(2-hydroxyethyl) Terephthalate / Poly(ethylene terephthalate) / Polycondensation / Sb(III) Catalyst / Phosphoric Acid / ${ }^{31} \mathrm{P}$ NMR /
\end{abstract}

It has been known that several side reactions such as etherification ${ }^{1,2}$ and thermal degradation ${ }^{3}$ are observed in the polycondensation of bis(2hydroxyethyl) terepththalate (BHET) or its oligomer. The side reactions sometimes lead to the deterioration of the physical and chemical properties of poly(ethylene terephthalate) (PET) obtained. ${ }^{2,4}$ In order to suppress these side reactions, phosphorus compounds such as phosphoric acid, ${ }^{5}$ phosphorous acid $^{6}$ and esters of these acids ${ }^{7}$ are usually used as modifiers of polycondensation catalysts. Actually, the thermal stability and whiteness of PET increase by the addition of phosphorus compounds. However, the role of phosphorus compounds in the catalytic polycondensation have scarcely been clarified.

The present authors previously reported the effect of phosphorus compounds on the polycondensation in the presence of $\mathrm{Zn}(\mathrm{II}), \mathrm{Co}(\mathrm{II})$, or $\mathrm{Mn}$ (II) catalyst. ${ }^{8}$ In this paper, the effect of phosphoric acid on the rate of the polycondensation and on side reactions catalyzed by antimony acetate was studied and the mechanisms for these reactions are discussed.

\section{EXPERIMENTAL}

\section{Materials}

BHET was prepared by the reaction of terephthalic acid with ethylene oxide as described previously. ${ }^{9}$

Catalysts and phosphoric acid were commercial products used without further purification.

\section{Polycondensation of $B H E T^{10}$}

In a 1.01 stainless steel autoclave, equipped with a stirrer, a distilling column and a thermometer, were placed $1.5 \mathrm{~mol}$ of BHET, $0.3 \mathrm{mmol}$ of antimony triacetate and a given amount of phosphoric acid. The polycondensation of BHET was carried out at $273^{\circ} \mathrm{C}$ under reduced pressure, ethylene glycol 
formed being continuously removed by distillation and collected in a trap cooled at the liquid nitrogen temperature.

\section{Analysis}

Determination of the Degree of Polycondensation. The intrinsic viscosity ([ $\eta]$ ) of PET was determined in a phenol-1,1,2,2-tetrachloroethane $(6: 4 \mathrm{w} / \mathrm{w}) \mathrm{mix}$ ture at $30^{\circ} \mathrm{C}$. The degree of polymerization $(\bar{P})$ was calculated from eq $1 .{ }^{11}$

$$
[\eta]=7.55 \times 10^{-4}(192 \bar{P}+62)^{0.685}
$$

Determination of the Carboxyl End Group. The carboxyl end group in PET was determined according to Pohl's method. ${ }^{12}$ After $0.1 \mathrm{~g}$ of PET was rapidly dissolved in $10 \mathrm{ml}$ of benzyl alcohol at $203^{\circ} \mathrm{C}$, the solution was then quickly mixed with chloroform and titrated with a $0.1 \mathrm{~N}$ solution of sodium hydroxide in benzyl alcohol using phenol phthalene as the indicator.

Determination of Diethylene Glycol. Diethylene glycol, obtained by the ethanolysis of PET, was determined by gas chromatography as described previously. ${ }^{13}$

Determination of Acetaldehyde. Acetaldehyde, generated by the side reaction in the polycondensation, was collected in a cold trap together with ethylene glycol. Acetaldehyde was determined using a Yanagimoto Model G-80 gas chromatography with a flame ionization detector. A $2 \mathrm{~m} \times 3 \mathrm{~mm}$ column packed with $10 \%$ Porapack $Q$ was used. The temperature was programed from $60^{\circ} \mathrm{C}$ to $200^{\circ} \mathrm{C}$ at $6^{\circ} \mathrm{C}$ $\min ^{-1}$.

Determination of ${ }^{31} \mathrm{P}$ NMR. The ${ }^{31} \mathrm{P}$ NMR measurements were made using a Japan Electron Optics Model JNM-FX-100. $\mathrm{C}_{6} \mathrm{D}_{6}$ and $85 \% \mathrm{H}_{3} \mathrm{PO}_{4}$ were used as a rock-signal and as an external standard, respectively. PET was dissolved in a $p$ chlorophenol-1,1,2,2-tetrachloroethane $(6: 4)$ mixture.

Determination of the $P$ Content of PET. The $\mathrm{P}$ content of PET was determined by a Rigaku Denki $\mathrm{X}$-ray fluorescence spectrometer.

\section{RESULTS AND DISCUSSION}

Polycondensation of BHET in the Presence of the Sb(III) Catalyst

The polycondensation rate of BHET in the presence of antimony acetate was compared in Figure 1

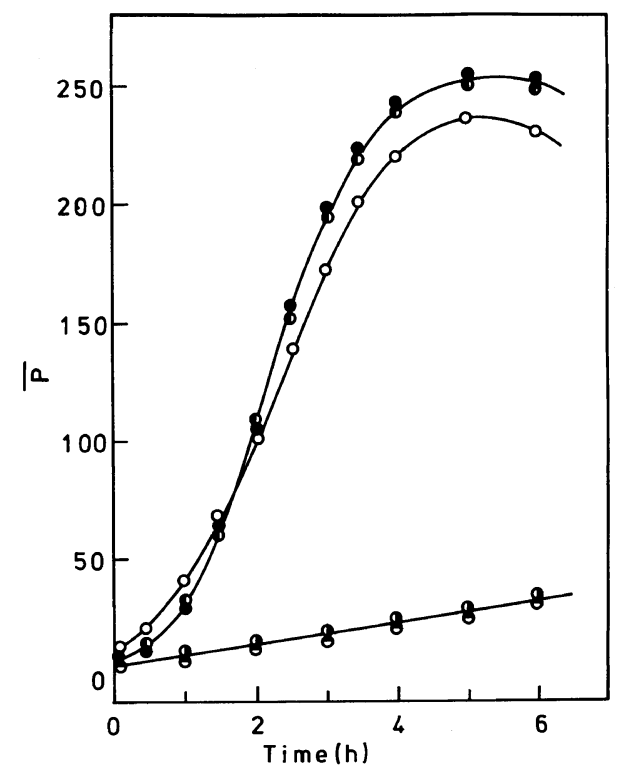

Figure 1. Effect of catalyst on the polycondensation rate of BHET: reaction temp, $273^{\circ} \mathrm{C}$; BHET, $1.5 \mathrm{~mol}$; (a) $\mathrm{O}, \mathrm{Sb}\left(\mathrm{OCOCH}_{3}\right)_{3}, 0.3 \mathrm{mmol}$; (b) O, $\mathrm{Sb}\left(\mathrm{OCOCH}_{3}\right)_{3}$, $0.3 \mathrm{mmol}+\mathrm{H}_{3} \mathrm{PO}_{4}, 0.3 \mathrm{mmol}$; (c) $\mathbf{O}, \mathrm{Sb}\left(\mathrm{OCOCH}_{3}\right)_{3}, 0.3$ $\mathrm{mmol}+\mathrm{H}_{3} \mathrm{PO}_{4}, 0.9 \mathrm{mmol}$; (d) $\ominus, \mathrm{SbPO}_{4}, 0.3 \mathrm{mmol}$; (e) o, without catalyst.

with that determined without a catalyst. The rate of polycondensation was very slow in the absence of the catalyst and the degree of polymerization $(\bar{P})$ was as low as 40, even by 6 hours of following of the polycondensation. The $\bar{P}$ of PET obtained in the presence of antimony acetate increased linearly with the reaction time after an induction period to give a higher-molecular-weight PET than that obtained in the absense of this compound. It is clear, therefore, that antimony acetate is an active catalyst for polycondensation. However, the rate of polycondensation began to slow down after 4 hours and even a decrease in $\bar{P}$ could be observed after 5 hours. These facts suggest that side reactions such as etherification and thermal degradation of PET occurred along with the polycondensation. ${ }^{10}$ The side reactions were confirmed by the formation of diethylene glycol and of acetaldehyde as shown later in detail.

Effect of Phosphoric Acid on the Activity of the $S b$ (III) Catalyst

The polycondensation of BHET was catalyzed by 
antimony triacetate in the presence of an equimolecular amount of phosphoric acid as shown in Figure 1(b). A longer induction period was observed in comparison with the case in which only antimony triacetate was present (Figure 1(a)). After the induction period, the rate of polycondensation was accelerated to give a higher-molecular-weight PET than the PET obtained in the absence of phosphoric acid as shown in Figure 1. This accelerating effect of phosphoric acid may be due to the generation of a cross-linked polymer by the reaction of BHET with trifunctional phosphoric acid, resulting in an apparent acceleration.

For the identification of phosphoric acid derivatives, the ${ }^{31} \mathrm{P}$ NMR spectrum of the polymer was measured and the result is shown in Figure 2(a). PET obtained in the presence of phosphoric acid has a singlet peak at $2.2 \mathrm{ppm}$ upfield from $\mathrm{H}_{3} \mathrm{PO}_{4}$. The ${ }^{31} \mathrm{P}$ NMR spectra of tris(2-methoxyethyl) phosphate $\left(\mathrm{O}=\mathrm{P}\left(\mathrm{OC}_{2} \mathrm{H}_{4} \mathrm{OCH}_{3}\right)_{3}\right)$ and tris(2-hydroxyethyl) phosphate $\left(\mathrm{O}=\mathrm{P}\left(\mathrm{OC}_{2} \mathrm{H}_{4} \mathrm{OH}\right)_{3}\right)$ appeared at 2.2 and $2.1 \mathrm{ppm}$, respectively. Therefore the ${ }^{31} \mathrm{P}$ resonance in PET may be assigned to phosphates

$\left(\mathrm{O}=\mathrm{P}\left(\mathrm{OC}_{2} \mathrm{H}_{4} \mathrm{OR}\right)_{3}, \mathrm{R}=-\mathrm{CO}-\mathrm{C}_{6} \mathrm{H}_{4} \mathrm{CO}_{2}-\right.$ or $\left.\mathrm{H}\right)$, produced by the reaction of phosphoric acid with BHET or ethylene glycol: that is, the alcohol groups attached to phosphate are either 2-hydroxyethyl end groups of the polymer or ethylene glycol.

If phosphoric acid is incorporated into the polymer, the PET having the cross-linked structure through the phosphoric acid unit is obtained, and hence, a higher-molecular-weight PET may be expected at higher concentrations of phosphoric acid. Further, the gelation of PET may occur in an extreme case. The possibility of the crosslinking, however, was ruled out because the polymer was soluble in a phenol-1,1,2,2-tetrachloroethane mixture, and $\bar{P}$ and the polycondensation rate did not depend on the concentration of phosphoric acid as shown in Figure 1(b, c). We consider, therefore, that phosphoric acid is converted into the phosphate of ethylene glycol. If so, low-molecular-weight phosphates will distill out from the system, the P content of PET will decrease with time, and the $P$ content in the distillate will increase. The variation of the $P$ content of PET with reaction time is shown in Figure 3. The $P$ content hardly decreased during the polycondensation in the absence of the $\mathrm{Sb}$ (III) catalyst but markedly decreased with reaction time in the presence of this catalyst. The ${ }^{31}$ P NMR spectra of the distillate during the polymerization with the catalyst show a major resonance at $1.1 \mathrm{ppm}$ and smaller resonance at

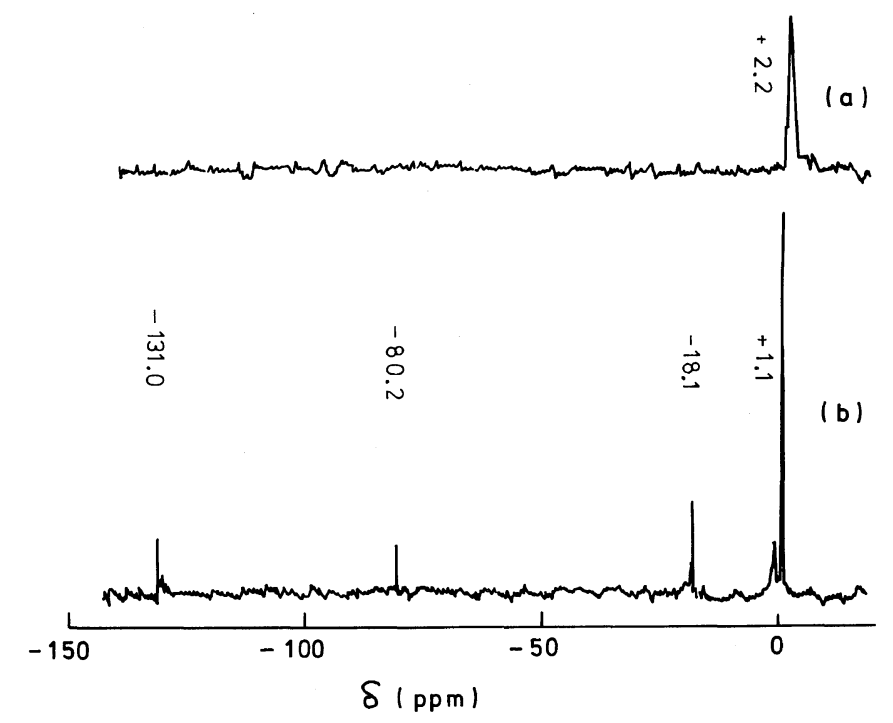

Figure 2. ${ }^{31} \mathrm{P}$ NMR spectra of PET (a), and distillate (b) in the polycondensation of BHET; catalyst, $\mathrm{Sb}\left(\mathrm{OCOCH}_{3}\right)_{3}+\mathrm{H}_{3} \mathrm{PO}_{4}$. 


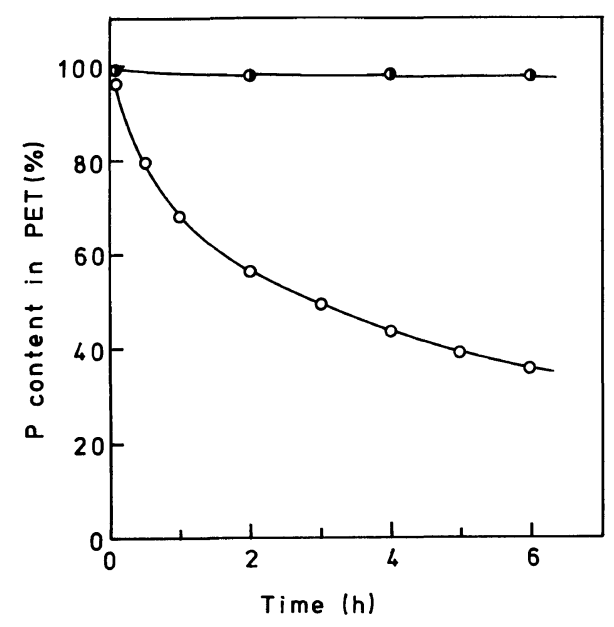

Figure 3. Time-conversion curves of $\mathrm{P}$ in the polycondensation of BHET: reaction temp, $273^{\circ} \mathrm{C}$; BHET, 1.5 mol; phosphoric acid, $0.3 \mathrm{mmol}$; $\mathrm{O}, \mathrm{Sb}\left(\mathrm{OCOCH}_{3}\right)_{3}, 0.3$ mmol; $\mathbf{O}$, without catalyst.

$-18.1,-80.2$ and -131.0 ppm as shown in Figure 2(b). The resonance at $1.1 \mathrm{ppm}$ was in accord with that of bis(2-hydroxyethyl) phosphate

$$
\left(\mathrm{O}=\mathrm{P}(\mathrm{OH})\left(\mathrm{OC}_{2} \mathrm{H}_{4} \mathrm{OH}\right)_{2}\right) \text {. }
$$

The resonances at -18.1 and $-131.0 \mathrm{ppm}$ were assigned to 2-hydroxyethyl ethylene phosphate

$$
\left(\begin{array}{l}
\mathrm{CH}_{2} \mathrm{O} \\
\mathrm{CH}_{2} \mathrm{O}
\end{array} \mathrm{CH}_{2}-\mathrm{P}(\mathrm{O}) \mathrm{OC}_{2} \mathrm{H}_{4} \mathrm{OH}\right)
$$

and 2-hydroxyethyl ethylene phosphite

$$
\left(\begin{array}{l}
\mathrm{CH}_{2} \mathrm{O} \\
\mathrm{CH}_{2} \mathrm{O}
\end{array}-\mathrm{P}-\mathrm{OCH}_{2} \mathrm{H}_{4} \mathrm{OH}\right)
$$

respectively. ${ }^{14}$

The fact that the P content of PET decreased only when the polycondensation was carried out in the presence of the $\mathrm{Sb}$ (III) catalyst suggests the presence of a reaction between the $\mathrm{Sb}(\mathrm{III})$ catalyst and phosphorus compound. If the $\mathrm{Sb}(\mathrm{III})$ catalyst is modified by the reaction with phosphorus compounds, the yield of by-products would also be affected in the presence of phosphoric acid, since byproducts are known to be generated by the reaction of BHET with catalysts. ${ }^{10}$

The effect of phosphoric acid on the yield of the main by-products, diethylene glycol and acetaldehyde, is shown in Figures 4 and 5, respectively. The addition of phosphoric acid leads to an increase in the diethylene glycol unit in the early stage of the polycondensation and to the decrease in acetal-

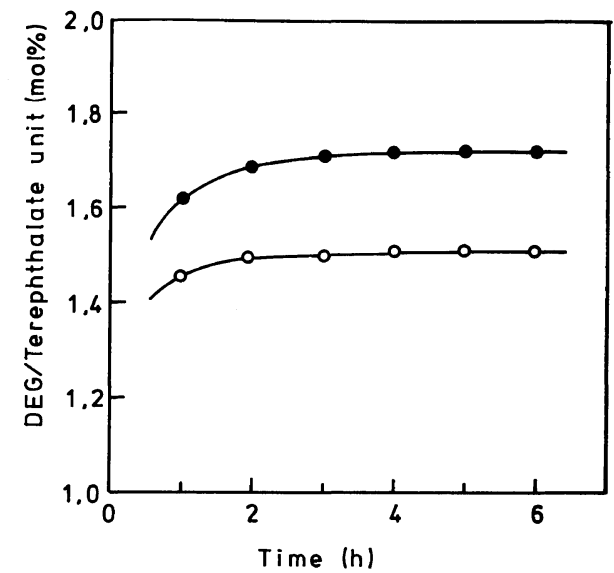

Figure 4. Effect of phosphoric acid on the formation of diethylene glycol unit (DEG) in the polycondensation of BHET: reaction temp, $273^{\circ} \mathrm{C}$; BHET, $1.5 \mathrm{~mol}$; $\bigcirc$, $\mathrm{Sb}\left(\mathrm{OCOCH}_{3}\right)_{3}, 0.3 \mathrm{mmol} ; \mathrm{O}, \mathrm{Sb}\left(\mathrm{OCOCH}_{3}\right)_{3}, 0.3 \mathrm{mmol}$ $+\mathrm{H}_{3} \mathrm{PO}_{4}, 0.3 \mathrm{mmol}$.

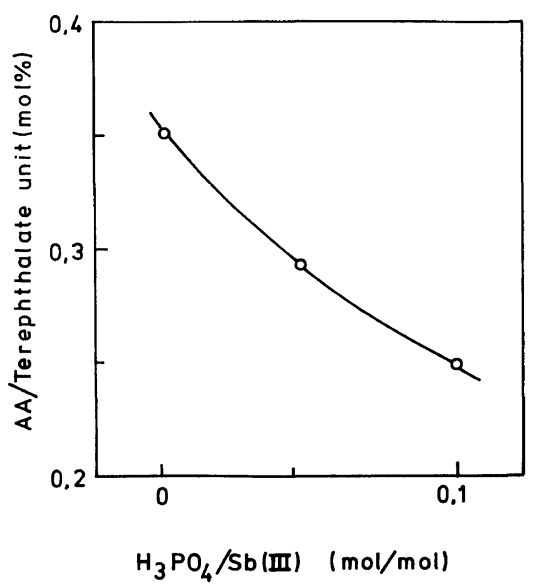

Figure 5. Effect of phosphoric acid on the formation of acetaldehyde (AA) in the polycondensation of BHET: reaction temp, $273^{\circ} \mathrm{C}$; $3.5 \mathrm{~h}$; BHET, $31.5 \mathrm{mmol}$; $\mathrm{Sb}\left(\mathrm{OCOCH}_{3}\right)_{3}, 0.05 \mathrm{mmol}$.

dehyde. These results indicate that phosphoric acid affects not only the apparent rate of polycondensation, but also the side reactions.

\section{Mechanism of Catalytic Polycondensation}

We reported previously ${ }^{10}$ that the polycondensation of BHET in the presence of a catalyst such as $\mathrm{Zn}(\mathrm{II}), \mathrm{Co}(\mathrm{II})$, or $\mathrm{Mn}(\mathrm{II})$ proceeded by way of the complex I, where the hydroxyl end groups of the 
polymer were activated by complexation with the metal of the catalyst. The polycondensation of BHET proceeds by the attack of this activated hydroxyl group on the carbon of the carbonyl group coordinated to the metal as shown in eq 2 . The formation of the diethylene glycol unit and of acetaldehyde is caused by the attack of the activated hydroxyl end group on the methylene carbon adjacent to the carboxyl group as shown in eq 3 and 4 .

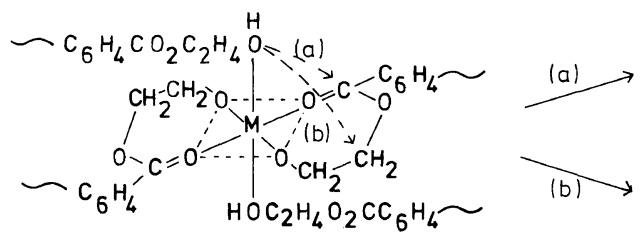

(I)

(a)

$$
\begin{aligned}
& \sim \mathrm{C}_{6} \mathrm{H}_{4} \mathrm{CO}_{2} \mathrm{C}_{2} \mathrm{H}_{4} \mathrm{O}_{2} \mathrm{CC}_{6} \mathrm{H}_{4}-
\end{aligned}
$$

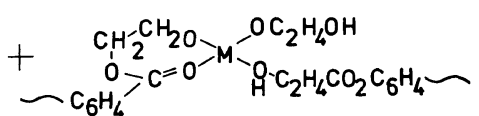

(b)

(II)

$$
\begin{aligned}
& \sim \mathrm{C}_{6} \mathrm{H}_{4} \mathrm{CO}_{2} \mathrm{C}_{2} \mathrm{H}_{4} \mathrm{OC}_{2} \mathrm{H}_{4} \mathrm{OH}
\end{aligned}
$$

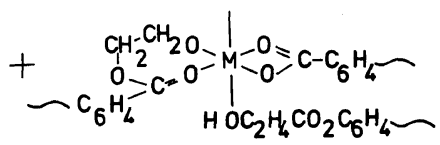

(III)

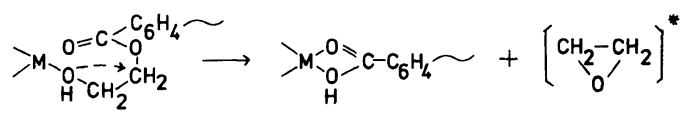

(II)

$$
\left[\mathrm{CH}_{2}-\mathrm{CH}_{0}^{\prime}\right]^{*} \rightarrow \mathrm{CH}_{3} \mathrm{C}_{\mathrm{H}}^{\prime \mathrm{O}}
$$

$$
\mathrm{M}=\mathrm{Zn}(\mathrm{II}), \mathrm{Co}(\mathrm{II}), \text { or } \mathrm{Mn}(\mathrm{II}) .
$$

Since the $\mathrm{Sb}(\mathrm{III})$ catalyst produces a complex coordinated by six oxygen atoms, ${ }^{15}$ the polycondensation with the $\mathrm{Sb}(\mathrm{III})$ catalyst should also proceed by way of a complex ${ }^{16}$ similar to that of the $\mathrm{Zn}(\mathrm{II})$, $\mathrm{Co}(\mathrm{II})$, or $\mathrm{Mn}(\mathrm{II})$ catalyst.

The presence of the induction period in the initial stage of the polycondensation catalyzed by antimony triacetate may be explained as follows. The coordination of the $\mathrm{C}=\mathrm{O}$ groups to $\mathrm{Sb}(\mathrm{III})$ in complex I is suppressed in the early stage of the polycondensation, because the hydroxyl end groups of the polymer can more easily coordinate to the $\mathrm{Sb}$ (III) catalyst than the $\mathrm{C}=\mathrm{O}$ groups. ${ }^{17}$ As the polycondensation proceeds, the concentration of hydroxyl end groups in the polymer decreases and the coordination of the $\mathrm{C}=\mathrm{O}$ groups to the $\mathrm{Sb}(\mathrm{III})$ catalyst become possible. In complex I $(\mathrm{M}=\mathrm{Sb}(\mathrm{III}))$, the activated hydroxyl end group easily attacks the coordinated carbonyl carbon (eq 2). ${ }^{16}$

The coordination of phosphoric acid to the $\mathrm{Sb}$ (III) catalyst may also be difficult in the early stage of the polycondensation, since the concentration of hydroxyl groups is high. It is known that phosphoric acid performs the dehydration reaction shown in eq $5,{ }^{2,8}$ and thus the yield of the diethylene glycol unit increases on addition of phosphoric acid, when phosphoric acid is not coordinated to the $\mathrm{Sb}$ (III) catalyst. This is shown in Figure 4.

$$
2 \underset{\mathrm{C}_{6} \mathrm{H}_{4} \mathrm{CO}_{2} \mathrm{C}_{2} \mathrm{H}_{4} \mathrm{OH} \stackrel{\mathrm{H}^{+}}{\longrightarrow}}{\longrightarrow \mathrm{C}_{6} \mathrm{H}_{4} \mathrm{CO}_{2} \mathrm{C}_{2} \mathrm{H}_{4} \mathrm{OC}_{2} \mathrm{H}_{4} \mathrm{O}_{2} \mathrm{CC}_{6} \mathrm{H}_{4} \sim+\mathrm{H}_{2} \mathrm{O}}
$$

Phosphoric acid not only performs the dehydration of BHET (eq 5) but also reacts with BHET to give a phosphate of BHET $\left(\mathrm{O}=\mathrm{P}\left(\mathrm{OC}_{2} \mathrm{H}_{4} \mathrm{OR}\right)_{3}\right.$, $\mathrm{R}=\mathrm{COC}_{6} \mathrm{H}_{4} \mathrm{CO}_{2} \mathrm{C}_{2} \mathrm{H}_{4} \mathrm{OH}$ ), which in turn reacts with ethylene glycol to give another tris(2hydroxyethyl) phosphate $\left(\mathrm{O}=\mathrm{P}\left(\mathrm{OC}_{2} \mathrm{H}_{4} \mathrm{OH}\right)_{3}\right)$. Since the 2-hydroxyethyl phosphate unit $\left(\mathrm{P}(\mathrm{O}) \mathrm{OC}_{2} \mathrm{H}_{4} \mathrm{OH}\right)$ has a structure similar to that of the 2-hydroxyethyl ester unit $\left(\mathrm{C}(\mathrm{O}) \mathrm{OC}_{2} \mathrm{H}_{4} \mathrm{OH}\right)$, it is reasonable to assume that the phosphate unit reacts with the $\mathrm{Sb}$ (III) catalyst to give complex IV.

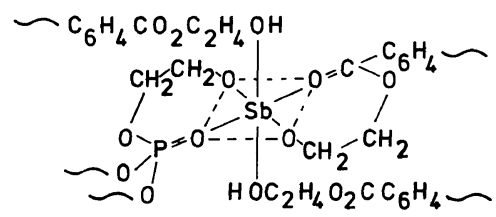

(IV)

The catalytic activity of antimony phosphate $\left(\mathrm{SbPO}_{4}\right)$ was compared in Figure 1 with that of antimony triacetate, the former showing no catalysis. Similarly, the reactivity of the $\mathrm{Sb}$ (III) catalyst in complex IV should be lower than that in complex I $(\mathrm{M}=\mathrm{Sb}(\mathrm{III}))$. If so, the polycondensation reaction and the side reactions (eq 3 and 4), all being due to complex I, may be suppressed by the addition of phosphoric acid. Figure $1(b, c)$ shows the suppression of polycondensation in the initial stage, and Figures 5 and 6 indicate the decrease of acetaldehyde 


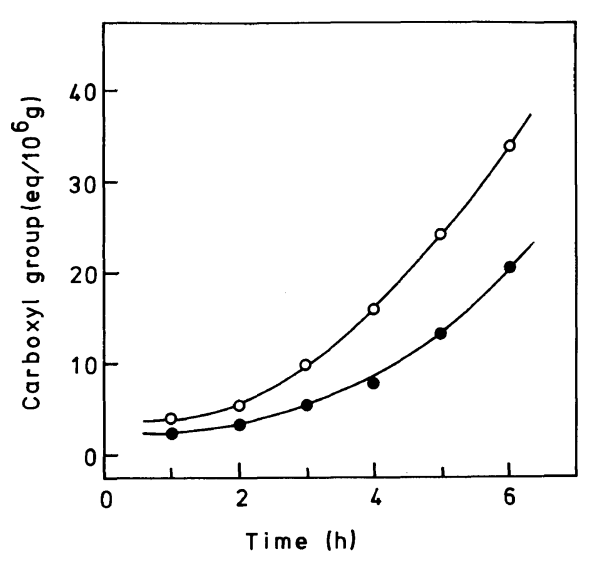

Figure 6. Effect of phosphoric acid on the formation of carboxyl groups in the polycondensation of BHET: reaction temp, $273^{\circ} \mathrm{C}$; $\mathrm{BHET}, 1.5 \mathrm{~mol} ; \mathrm{O}$, $\mathrm{Sb}\left(\mathrm{OCOCH}_{3}\right)_{3}, 0.3 \mathrm{mmol}$; $, \mathrm{Sb}\left(\mathrm{OCOCH}_{3}\right)_{3}, 0.3 \mathrm{mmol}$ $+\mathrm{H}_{3} \mathrm{PO}_{4}, 0.3 \mathrm{mmol}$.

and the carboxyl end groups, respectively.

It is known ${ }^{10,18}$ that the reaction of the complexed carboxyl group with the 2-hydroxyethyl ester group (eq 6) is much slower than the polycondensation of BHET (eq 2). Since phosphoric acid suppress the formation of carboxyl end groups, it prevents the reduction of the polycondensation due to reaction 6 . Therefore the rate of the polycondensation in the presence of phosphoric acid is larger than that in the absence of this acid as shown in Figure 1.

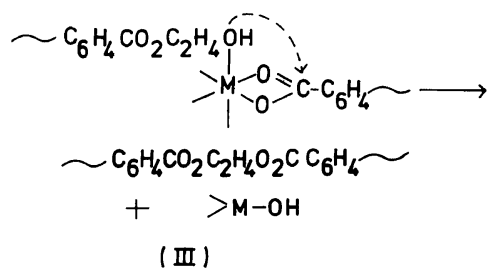

In summary, phosphoric acid reacts with the $\mathrm{Sb}$ (III) catalyst to give catalytic complex IV, where side reactions, occurring by way of complex I, are suppressed. The result is the acceleration of the rate of polycondensation. The increase in the diethylene glycol unit in the early stage of the polycondensation is due to the catalytic action of free phosphoric acid, which is present only in the early stage of the polycondensation.

Acknowledgment. The authors wish to express their sincere gratitude to Professor S. Nozakura and Associate Professor M. Kamachi of Osaka University for reading this manuscript and giving much kind advice. Also, they should like to thank Mr. M. Tahara, director and general manager of the Development and Research Center, Toyobo Co., Ltd., for granting permission to publish this work.

\section{REFERENCES}

1. S. G. Hovenkamp and J. P. Munting, J. Polym. Sci., $A-1,8,679$ (1970).

2. H. R. Penton, Jr., and H. Bouman, Polym. Prepr. Am. Chem. Soc., Div. Polym. Chem., 17, 521 (1976).

3. L. H. Buxbaum, Angew. Chem., Int. Ed., 7, 182 (1968).

4. J. R. Kirby, A. J. Baldwin, and R. H. Heidner, Anal. Chem., 37, 1306 (1965).

5. Du pont, U.S. Patent 3028366 (1962).

6. Imperial Chem. Ind., Jpn. Patent 237602 (1957).

7. Kanebo, Jpn. Patent 793249 (1975).

8. H. Kamatani and S. Konagaya, Kobunshi Ronbunshu, 36, 293 (1979).

9. H. Kamatani, Nippon Kagaku Kaishi 1505 (1977).

10. H. Kamatani and S. Konagaya, Kobunshi Ronbunshu, 35, 787 (1978).

11. H. Yokoyama, T. Sano, T. Chijiiwa, and R. Kajiya, $J$. Jpn. Petrol. Inst., 21, 58 (1978).

12. H. A. Pohl, Anal. Chem., 26, 1614 (1954).

13. H. Kamatani, Nippon Kagaku Kaishi, 1271 (1978).

14. R. A. Y. Jones and A. R. Katritzky, J. Chem. Soc., 4376 (1960).

15. K. Tanabe, T. Sumiyoshi, and K. Shibata, Bull. Chem. Soc. Jpn., 47, 1064 (1974).

16. K. Tomita, Kobunshi Ronbunshu, 33, 96 (1976).

17. G. Tsimmerman and E. Shaaf, Polym. Sci. USSR, 15, 472 (1973).

18. Toyobo, Jpn. Patent 758646 (1974). 